\title{
Retinitis pigmentosa with concomitant essential iris atrophy and glaucoma - case report
}

\author{
This article was published in the following Dove Press journal: \\ Clinical Ophthalmology \\ 26 November 2015 \\ Number of times this article has been viewed
}

\author{
Sérgio Henrique Sampaio \\ Meirelles ${ }^{1-3}$ \\ Aline Sá Barreto' \\ Eduardo Scaldini Buscacio ${ }^{1,2}$ \\ Elke Shinzato 1,2,4 \\ Lia Florim Patrão' \\ Mauro Sérgio de Oliveira \\ Silva' \\ 'Piedade Municipal Hospital, Rio de \\ Janeiro, ${ }^{2}$ Federal University of Rio de \\ Janeiro, ${ }^{3}$ Estacio de Sá University, Rio \\ de Janeiro, Brazil; ${ }^{4}$ Ocular Ultrasound \\ Department, Clinical Hospital of \\ the University of São Paulo Medical \\ School, São Paulo, Brazil
}

Correspondence: Sérgio Henrique Sampaio Meirelles

Piedade Municipal Hospital, Rua da Capela, 96 Piedade, Rio de Janeiro, RJ, Brazil

Tel +55 2I 3III 6540

Email serhme@terra.com.br
Purpose: To report a case of a young patient with retinitis pigmentosa (RP), essential iris atrophy, and glaucoma.

Case report: This report presents a case of a 22 -year-old female patient with unilateral glaucoma, increased intraocular pressure, increased cup-disc ratio, iris atrophy, peripheral anterior synechiae, and bilateral RP.

Discussion: The patient presented glaucoma due to the iridocorneal endothelial syndrome, despite low age. RP is a bilateral disorder that may be associated with angle-closure glaucoma.

Keywords: ocular hypertension, ICE syndrome, secondary glaucoma, retinal degeneration

\section{Introduction}

Essential iris atrophy is one of the subtypes of iridocorneal endothelial (ICE) syndrome, which is a spectrum of disorders characterized by corneal proliferative endotheliopathy, associated with corneal edema, anterior chamber and iris stroma abnormalities, and glaucoma. ${ }^{1}$ Other variants of ICE syndrome are Chandler's syndrome and Cogan-Reese syndrome. The essential iris atrophy usually affects females, generally over 30 years old. It is unilateral, and it is associated with iris holes, peripheral anterior synechiae, and corneal alterations. ${ }^{1}$ Approximately $50 \%$ of the cases present glaucoma, and it is probably caused by peripheral anterior synechiae and by a cellular membrane that covers the trabecular surface. The treatment for glaucoma is clinical; however, there is frequent surgical indication of trabeculectomy.

Retinitis pigmentosa (RP) is characterized by progressive decrease in night vision and progressive visual field loss due to cellular retinal dystrophy. The fundoscopy shows characteristic bone-spicules pigment. ${ }^{2} \mathrm{RP}$ does not present a defined inheritance pattern, and it might occur in an autosomal dominant, recessive, or X-linked fashion. ${ }^{3}$ It can also be related to other systemic and ocular manifestations.

\section{Case report}

A 22-year-old white female patient reported the diagnosis of RP that she had 7 years before. Having gone through many examinations along this period, 1 year ago, it was diagnosed increased intraocular pressure (IOP) in the right eye (OD). The patient had misused hypotensive eye drops: prostaglandin analogs, carbonic anhydrase inhibitors, and B-adrenergic antagonists. She had interrupted the use of eye drops for 3 months. There was no family history of either RP or glaucoma. No ethical approval was required for this procedure. Patient consent was obtained before undergoing treatment.

In the ophthalmic examination, the best-corrected visual acuity was OD: 20/50 $(-1,00$ cyl $\times 115)$ and left eye $($ OS $): 20 / 25(+2,00 \mathrm{sph}-1,00$ cyl $\times 10)$. The slit lamp examination showed multiple iris holes and corectopia in OD (Figures 1 and 2), clear 


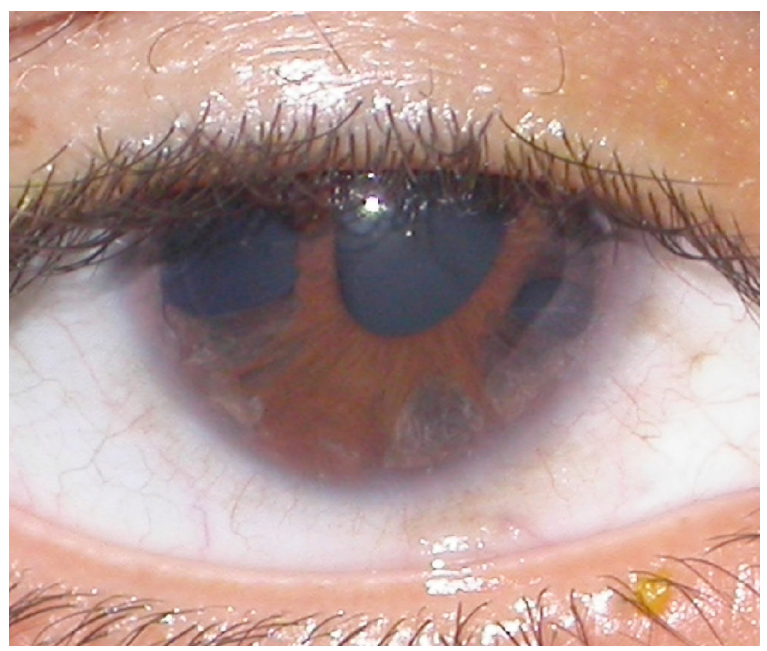

Figure I Iris holes and corectopia in OD.

Abbreviation: OD, right eye.

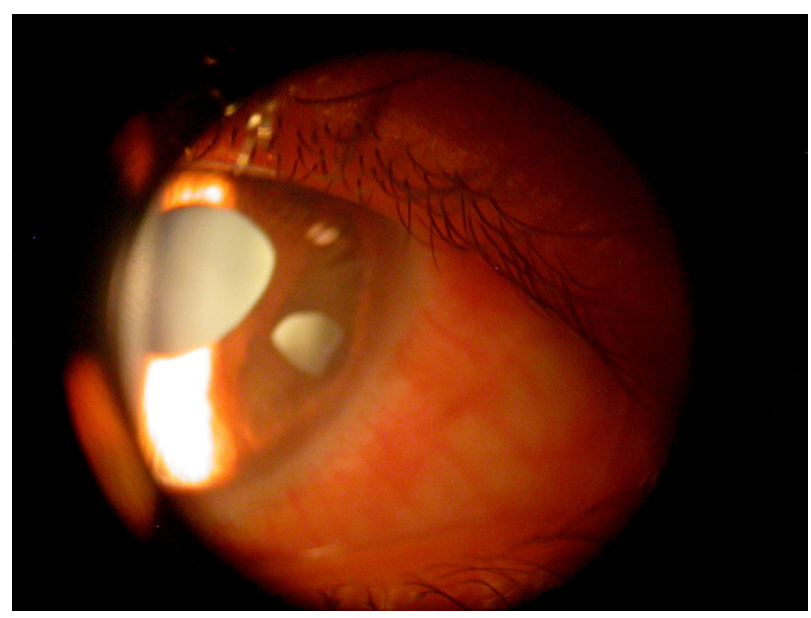

Figure 2 Iris holes and corectopia in OD. Abbreviation: OD, right eye.

cornea in both eyes (OU), and no alterations in OS. IOP by Goldmann applanation tonometry was OD: $34 \mathrm{mmHg}$ and OS: $16 \mathrm{mmHg}$ at $3 \mathrm{pm}$. The gonioscopy revealed $360^{\circ}$ isolated peripheral anterior synechiae in OD (Figure 3) and a visible open-angle up to ciliary body in OS. The fundoscopy (Figures 4 and 5) presented cup-disc ratio 0.9 vertical $(\mathrm{V}) \times 0.9$ horizontal $(\mathrm{H})$, visible lamina cribrosa pores, preserved macula, and peripheral pigment mobilization in OD. In OS, the fundoscopy revealed cup-disc ratio $0.3 \mathrm{~V} \times 0.3 \mathrm{H}$, preserved macula, and peripheral pigment mobilization. The automated perimetry (Figures 6 and 7) and manual perimetry (Figures 8 and 9) showed central island vision in OD and ring scotoma in OS. The ultrasound pachymetry was $524 \mu \mathrm{m}$ and $530 \mu \mathrm{m}$ in OD and OS, respectively. The specular microscopy revealed pleomorphism and polymegathism in OU (Figures 10 and 11). Fluorescein angiography featured

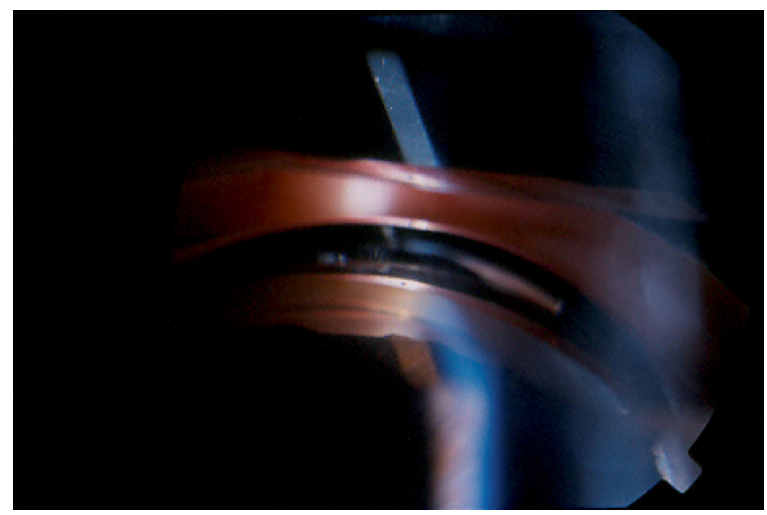

Figure 3 Peripheral anterior synechiae in OD. Abbreviation: OD, right eye.

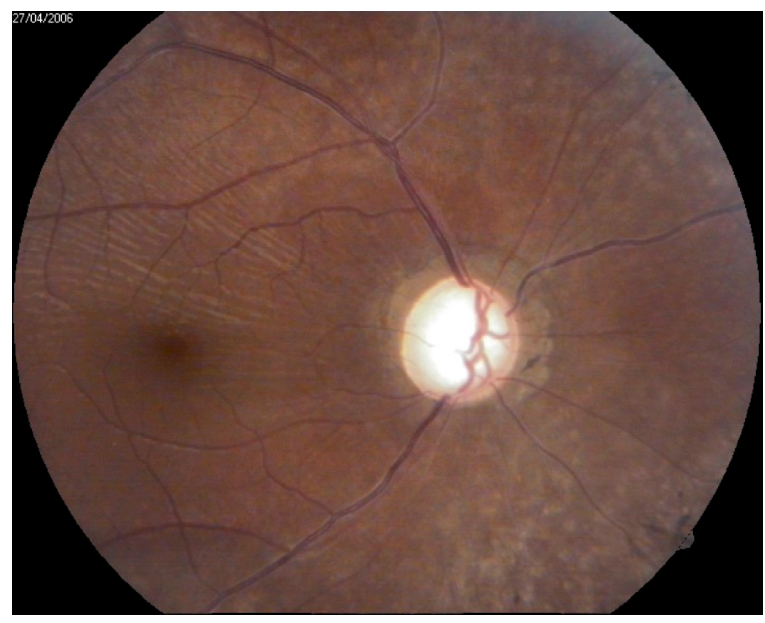

Figure 4 Retina and optic disc in OD. Abbreviation: OD, right eye.

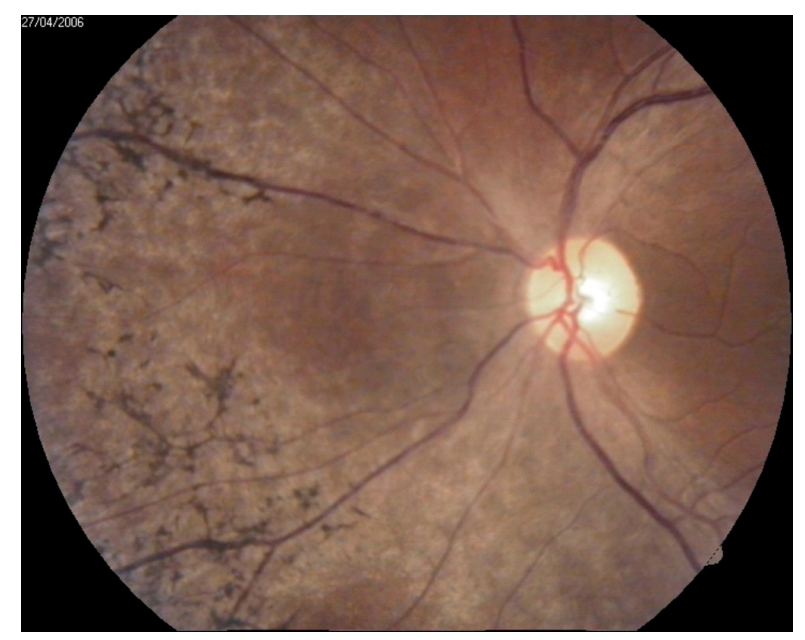

Figure 5 Retina and optic disc in OS. Abbreviation: OS, left eye. 
Name:

First name:

ID \#:

Birth date:

Age:

Sex:

Refr S/C/A:

Acuity:

IOP:

Diagnostics:

Patient file:
Eye/pupil (mm):

Date/time:

Test duration:

Program/code:

Stages/phases:

Strategy/method:

Test target/duration:

Background:

Questions/repetitions:

Catch trials:
Right (OD)/4.0

20/04/2006 11:10

$6: 3$

dG $1 X / 0$

$4 / 1$

Dynamic/normal

III/100 ms

$31.4 \mathrm{asb}$

$110 / 0$

pos $0 / 5$, neg $5 / 6$
Grayscale of values $30^{\circ}$

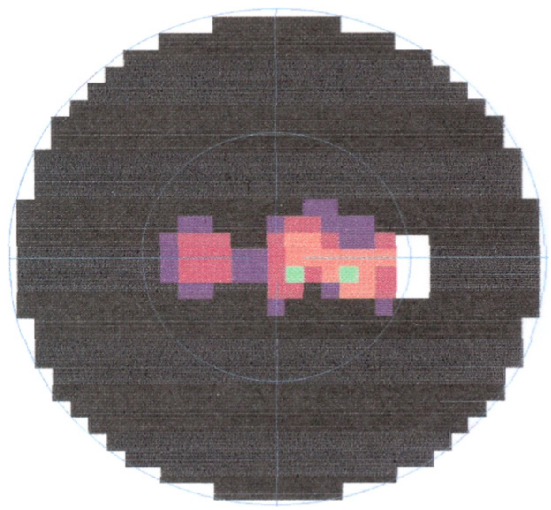

Values $30^{\circ}$
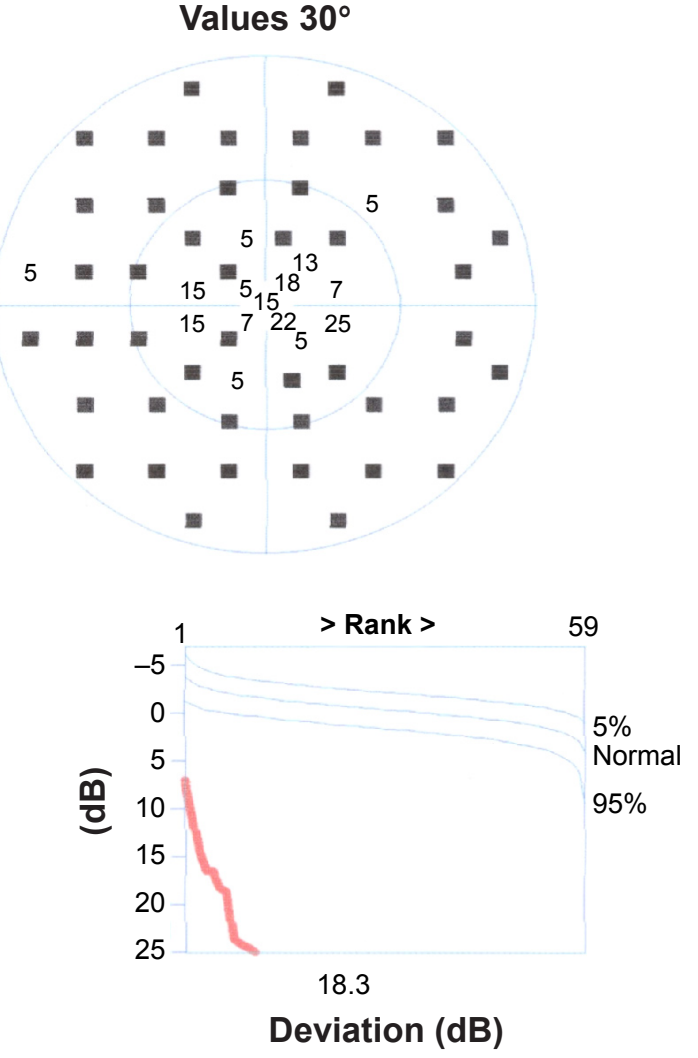

\section{Corrected probability}
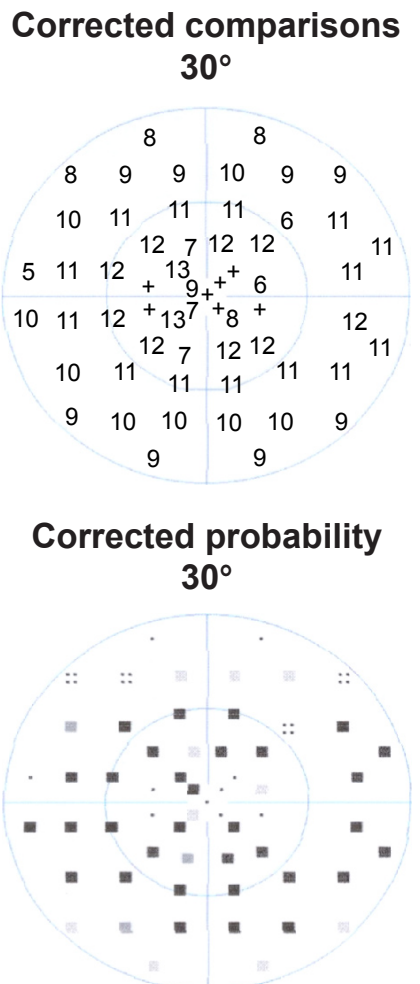

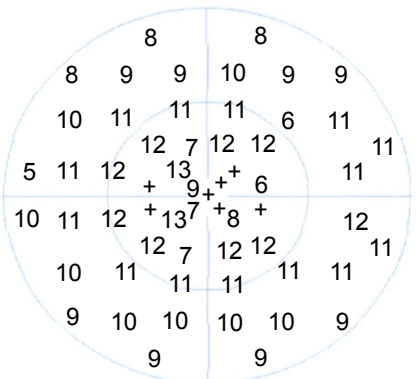

Probability $30^{\circ}$

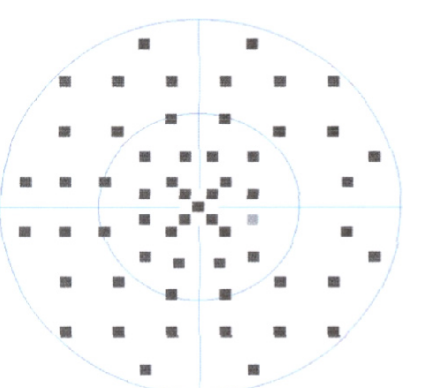

Figure 6 Automated perimetry in OD.

Abbreviations: OD, right eye; MS, mean sensitivity; MD, mean defect; LV, loss variance; CLV, corrected loss variance; SF, short-term fluctuation; RF, reliability factor; IOP, intraocular pressure; Refr S/C/A, Refraction spheric/cylinder/ axis. 


\section{Name:}

First name:

ID \#:

Birth date:

Age:

Sex:

Refr S/C/A:

Acuity:

IOP:

Diagnostics:

Patient file:

\section{Eye/pupil (mm):}

Date/time:

Test duration:

14/01/1984 Program/code:

22 \# stages/phases:

Female Strategy/method:

+2.00./-1.00./10

Test target/duration:

Background:

\# questions/repetitions:

\# catch trials:
Left (OS)/4.0

20/04/2006 11:18

$6: 7$

dG1X/0

$4 / 1$

Dynamic/normal

III/100 ms

$31.4 \mathrm{asb}$

$166 / 1$

pos $0 / 8$, neg $1 / 9$
Grayscale of values $30^{\circ}$

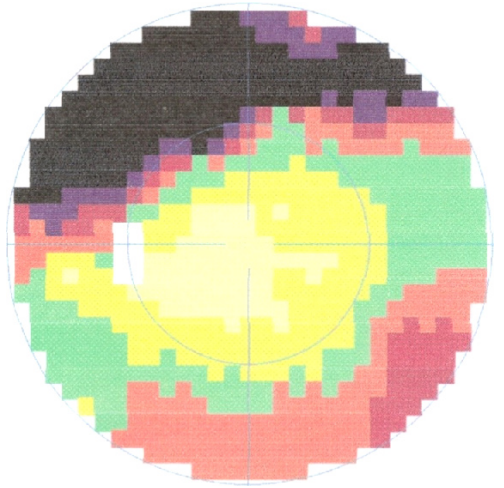

Values $30^{\circ}$

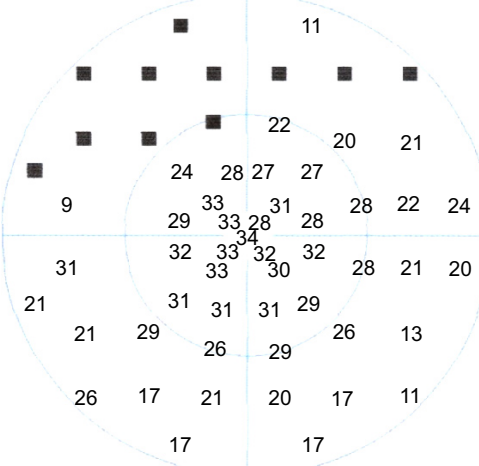

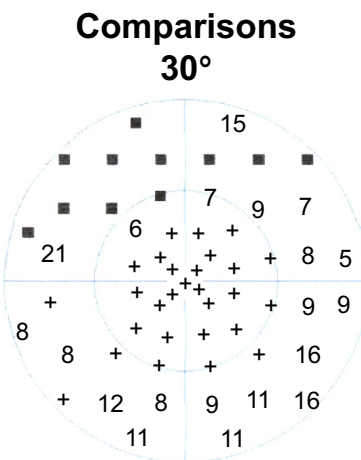

Probability $30^{\circ}$

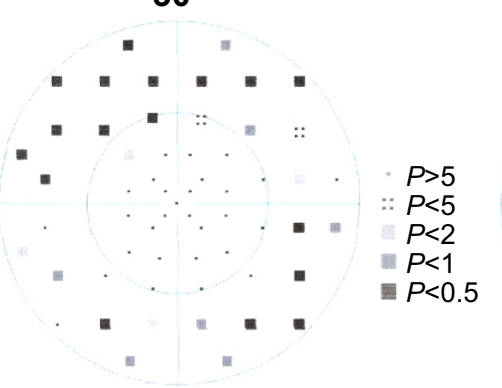

Corrected comparisons $30^{\circ}$

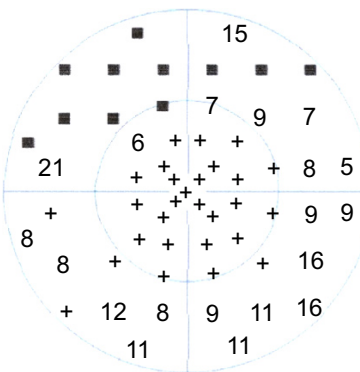

Corrected probability

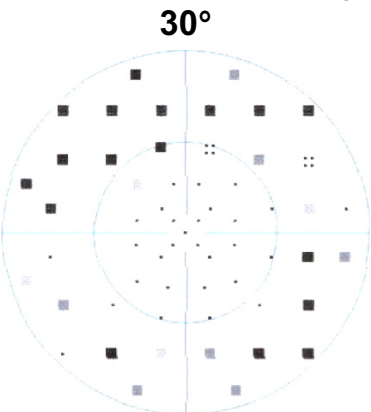

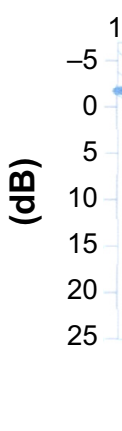

$>$ Rank >

59

$5 \%$

Normal

95\%

0.0

\section{Deviation (dB)}

Figure 7 Automated perimetry in OS.

Abbreviations: OS, left eye; MS, mean sensitivity; MD, mean defect; LV, loss variance; CLV, corrected loss variance; SF, short-term fluctuation; RF, reliability factor; IOP, intraocular pressure; Refr S/C/A, Refraction spheric/cylinder/ axis. 


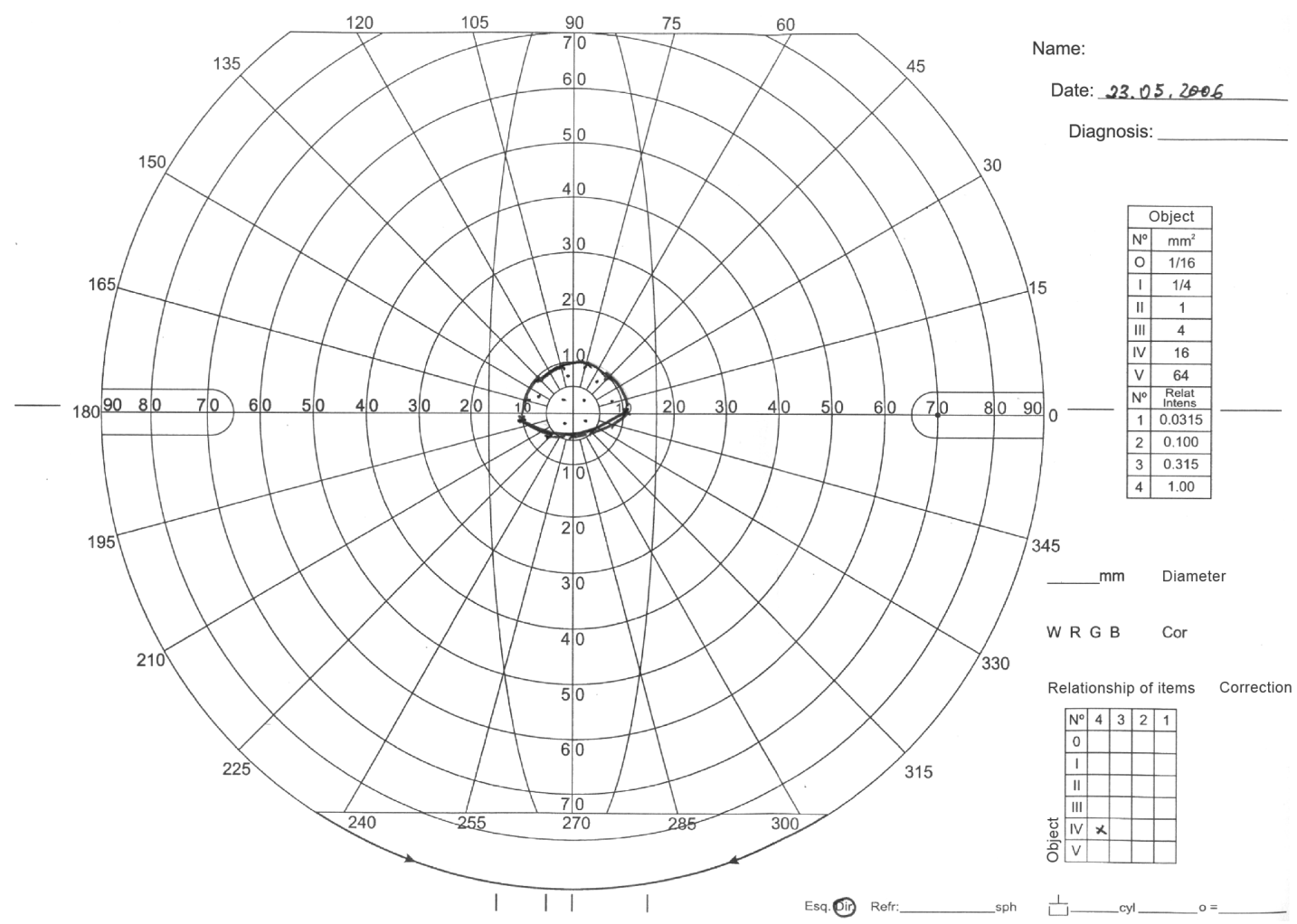

Figure 8 Manual perimetry in OD.

Abbreviation: $\mathrm{OD}$, right eye.

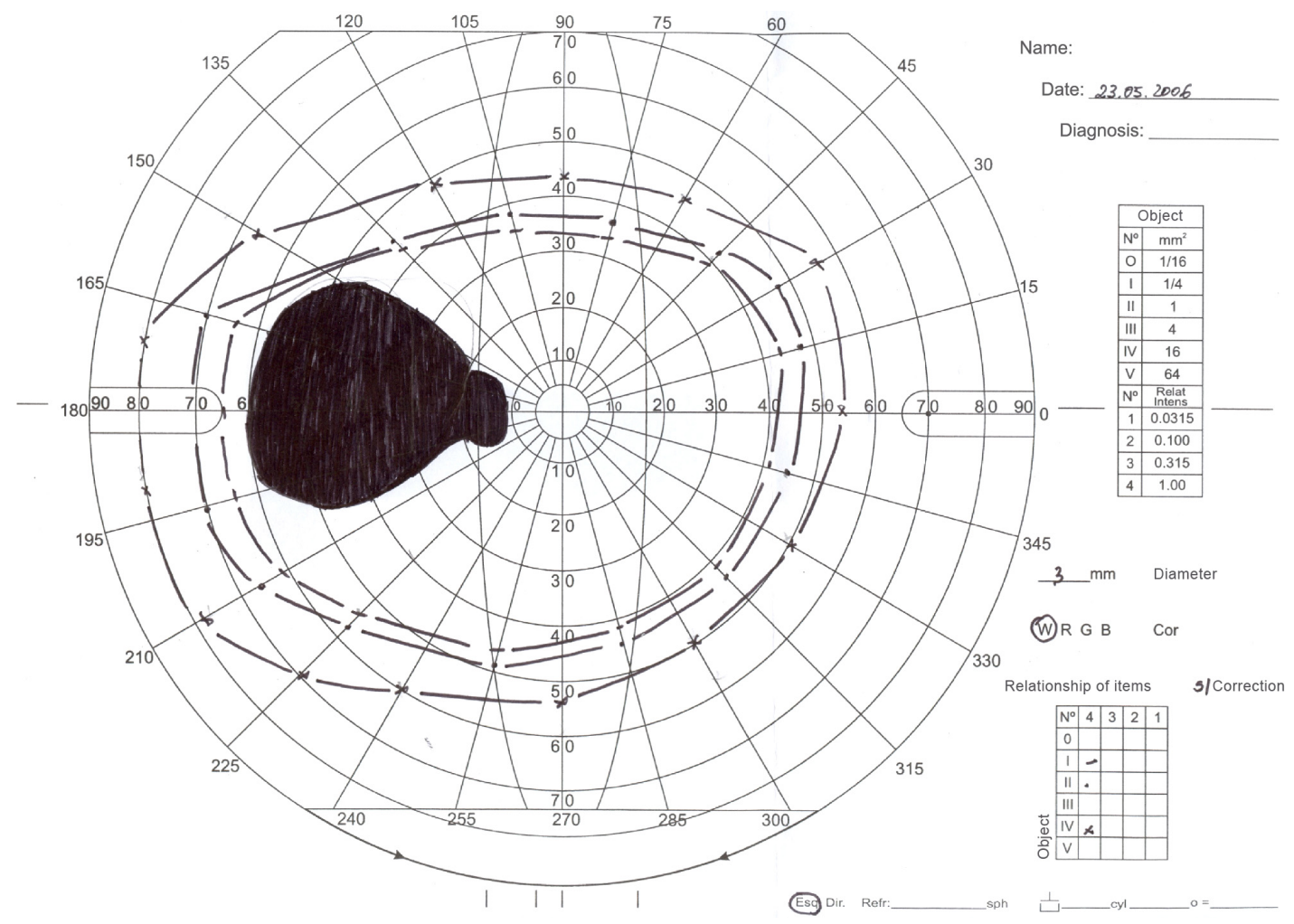

Figure 9 Manual perimetry in OS.

Abbreviation: OS, left eye. 

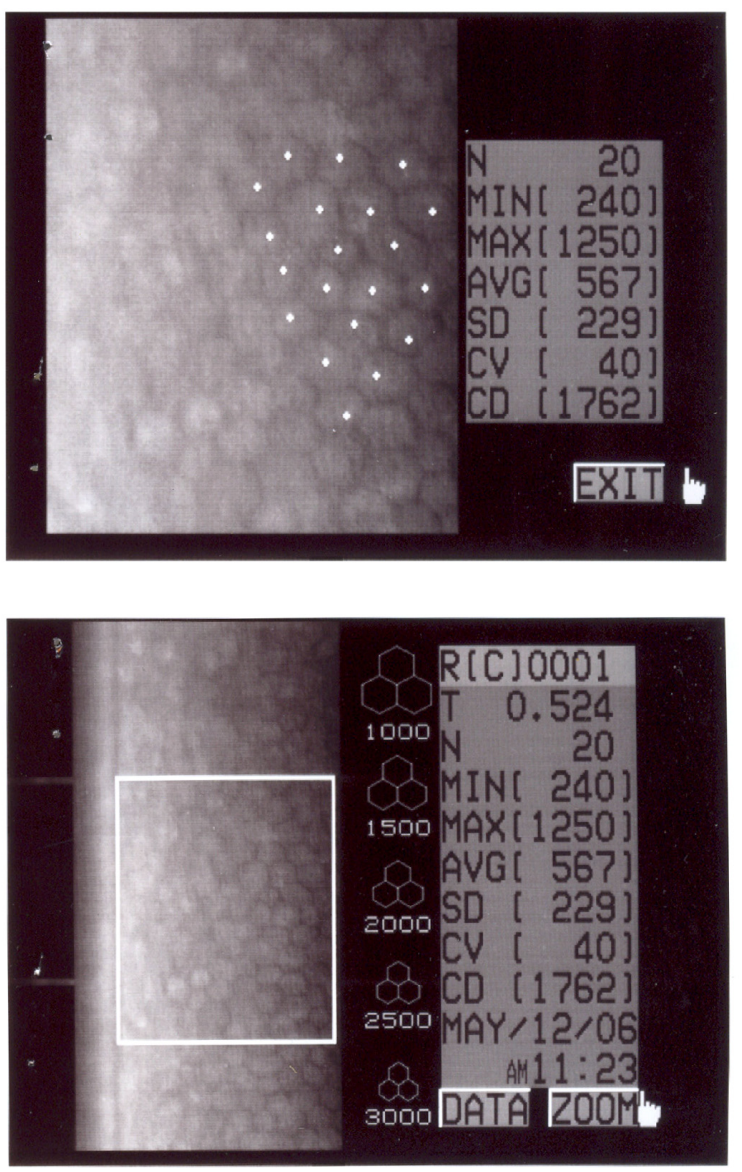

Figure 10 Specular microscopy in OD.

Abbreviation: OD, right eye.

blocked fluorescence in the peripheral pigment mobilization areas in OU.

After failure of the clinical treatment to diminish IOP in OD, trabeculectomy was performed in this eye and IOP was controlled.

\section{Discussion}

We have reported the case of a young patient presenting with RP and ICE syndrome with glaucoma. Although there are some reports of association of RP and glaucoma in the literature, we have not found any report of association between RP and ICE syndrome at PubMed.

The most frequent glaucoma associated with RP is angleclosure glaucoma. ${ }^{2,46}$ The prevalence of glaucoma in patients with RP can be up to $2.3 \%{ }^{4}$ However, a study of 40 patients with RP found a prevalence of $12.5 \%$ of primary glaucoma. ${ }^{7}$ In the literature, there are reports of glaucoma associated with RP in inherited isolated or secondary cases, such as Sturge-Weber syndrome, ${ }^{8,9}$ retinal neovascularization, ${ }^{10}$ familial nephropathy, ${ }^{11}$ bilateral ectopia lentis, ${ }^{12}$ and Fuchs
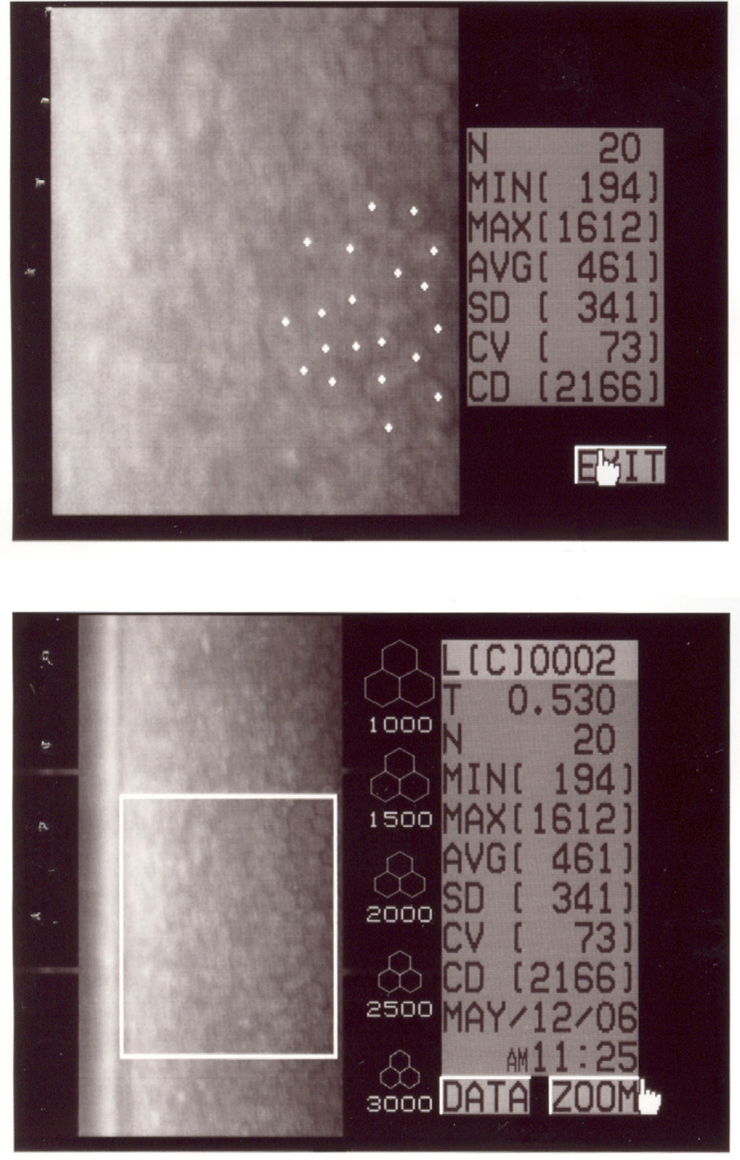

Figure I I Specular microscopy in OS. Abbreviation: OS, left eye.

heterochromic cyclitis. ${ }^{13}$ There are also case reports of patients with RP who mimic glaucomatous visual field defect ${ }^{14}$ and abnormal nerve fiber layer of the retina, similar to those found in patients with glaucoma. ${ }^{15}$

In this case, we believe that glaucoma is associated with ICE syndrome because the patient has unilateral glaucoma and iris essential atrophy in the same eye. The patient also presents alterations in specular microscopy and in the anterior chamber in OD, which might be related to essential iris atrophy. The perimetry examinations demonstrate a glaucoma typical defect in OD and a RP typical defect in OS.

There was no response to the clinical treatment with hypotensive eye drops. Therefore, the patient underwent trabeculectomy in OD, and the IOP was controlled.

\section{Acknowledgment}

Marucia Patrão assisted with the manuscript preparation.

\section{Disclosure}

The authors declare that there are no conflicts of interest. 


\section{References}

1. Shields MB, Bourgeois JE. Glaucoma associated with primary disorders of the corneal endothelium. In: Retch R, Shields MB, Krupin T, editors. The Glaucomas. St Louis: Mosby; 1996:957-974.

2. Pruett RC. Retinitis pigmentosa: clinical observations and correlations. Trans Am Ophthalmol Soc. 1984;81:693-735.

3. Carr RE, Heckenlively JR. Chapter 24: Hereditary pigmentary degeneration of the retina. In: Duane TD, Jaeger EA, editors. Clinical Ophthalmology. Vol. 3. Philadelphia: Harper and Row;1987:1-28.

4. Peng DW. Retinitis pigmentosa associated with glaucoma. Chinese Journal of Ophthalmology (Zhonghua yan ke za zhi). 1992;27(5): 262-264. Chinese.

5. Malta RFS, Takahashi W, Nicolela MT, Soriano D. Glaucoma agudo primário e retinose pigmentar. Rev Bras Oftalmol. 1994;53(2):47-50.

6. Omphroy CA. Sector retinitis pigmentosa and chronic angle-closure glaucoma: a new association. Ophthalmologica. 1984;189(1-2):12-20.

7. Kogbe OI, Follmann P. Investigations into the aqueous humour dynamics in primary pigmentary degeneration of the retina. Ophthalmologica. 1975;171(2):165-175.

8. Maul ED, Kass MA. Retinitis pigmentosa associated with nevus flammeus and unilateral glaucoma. Ann Ophthalmol. 1977;9(5):603-605.
9. Filatov V, Guyer DR, Lustbader JM, Berkow JW. Dislocation of the crystalline lens in a patient with Sturge-Weber syndrome. Ann Ophthalmol. 1992;24(7):260-262.

10. Uliss AE, Gregor ZJ, Bird AC. Retinitis pigmentosa and retinal neovascularization. Ophthalmology. 1987;93(12):1599-1603.

11. Fiore C, Santoni G, Reggiani FM, Buoncristiani U, Pasticci B. Familial nephropathy with retinitis pigmentosa and closed-angle glaucoma. Ophthalmic Paediatr Genet. 1985;5(1-2):39-49.

12. Halpern BL, Sugar A. Retinitis pigmentosa associated with bilateral ectopia lentis. Ann Ophthalmol. 1981;13(7):823-824.

13. Vuorre I, Saari M, Tiilikainen A, Rasanen O. Fuch's heterochromic cyclitis associated with retinitis pigmentosa: a familial study. Can $J$ Ophthalmol. 1979;14(1):10-16.

14. Dauber SL, Masselos K, Brown TM, Figuera EC, Pandya VB, Francis IC. Atypical retinitis pigmentosa masquerading as primary open angle glaucoma. J Glaucoma. 2008;17(3):248. Available from: http://dx.doi org/10.1097/IJG.0b013e31816c4d9f. Author reply 248-249.

15. Trobe JD, Bergsma DR. Atypical retinitis pigmentosa masquerading as a nerve fiber bundle lesion. Am J Ophthalmol. 1975;79(4):681-686.
Clinical Ophthalmology

\section{Publish your work in this journal}

Clinical Ophthalmology is an international, peer-reviewed journal covering all subspecialties within ophthalmology. Key topics include: Optometry; Visual science; Pharmacology and drug therapy in eye diseases; Basic Sciences; Primary and Secondary eye care; Patient Safety and Quality of Care Improvements. This journal is indexed on

Submit your manuscript here: http://www.dovepress.com/clinical-ophthalmology-journal

\section{Dovepress}

PubMed Central and CAS, and is the official journal of The Society of Clinical Ophthalmology (SCO). The manuscript management system is completely online and includes a very quick and fair peer-review system, which is all easy to use. Visit http://www.dovepress.com/ testimonials.php to read real quotes from published authors. 